\title{
An Innovative Tool for the Evaluation of Nox Emissions from Road Traffic
}

\author{
Rozalia Melania Boitor (iD) ${ }^{1}$, Rodica Dorina Cadar (iD) ${ }^{2}$, Petru Daniel Maran (iD) 3 , \\ Marco Petrelli \\ ${ }^{1-3}$ Transport Systems Research Group, Technical University of Cluj-Napoca, Cluj-Napoca, Romania \\ ${ }^{4}$ Department of Engineering, Roma Tre University, Roma, Italia
}

Received 4 February 2020; accepted 31 March 2020

\begin{abstract}
In the last years, there was great interest in the development of tools for an effective evaluation of road transport pollutant-related emissions, especially in the urban areas. This paper represents an innovative approach for identifying criticalities about pollutant emissions associated with road traffic and for defining effective policies in order to decrease pollutant emissions. The proposed tool concerns the development of an emission indicator, a proxy measure, which is useful for the assessment of emission problems, based on the use of GPS (Global Positioning System) instantaneous vehicle speed data. The tool can be considered an innovative and adequate solution in many cases in which the development of a valid and robust traffic simulation model, especially DTA (dynamic traffic assignment) is not available in the medium- and short-term horizon. The methodological process concerns the monitoring of road traffic conditions using GPS data from probe vehicles in combination with the use of GIS (Geographic Information System) for the estimation of an emission indicator. The tool has been tested on a real case study in the city of Cluj in Romania for the NOx emissions. The results show the utility of the tool in supporting policy and decision making, due to its ease of application and consistency, especially in defining critical areas.
\end{abstract}

Keywords: $\mathrm{NO}_{\mathrm{x}}$ emissions, spatial analysis, GPS instantaneous vehicle speed, COPERT model, urban road traffic.

\section{Introduction}

Transport-related emissions show a significant growth over the past decade and this trend is expected to continue on the long term. In this respect, decarbonising the transport sector by eliminating fossil fuel could be a very effective policy on the long term. Meanwhile, smaller scale interventions in the urban area are already possible by implementing investments in clean infrastructure (Zhang et al., 2018) or traffic management. Urban areas are acknowledged to have the highest share in generating pollution related to transport and to face the most negative direct impact (Covrig et al., 2016; Roșu et al., 2018). Traffic emissions are included in the background air pollution. However, their impact is very important (Alam et al., 2017; Banica et al., 2017; Condurat, 2016; Tongwane et al., 2015).

Specifically, the impact is more significant in areas where there is a large component of heavy traffic (Laña et al., 2016) or where car traffic level ranges from moderate to heavy (Matz et al., 2018). Taking into consideration this specific context, pollutant emissions related to mobility are strictly correlated with the traffic dynamics such as queue, spillback and speed variation (Afotey et al., 2013; Barth \& Boriboonsomsin, 2008; Zhao et al., 2017).

Sustainable Urban Mobility Plans (SUMPs) (EC, 2013; ELTIS, 2014) are strategic documents for transport planning. They promote more sustainable mobility systems and they analyse the impact of any trends or policies for urban mobility in which the estimation of pollutants is an important project indicator. In some cases, urban regeneration models have been developed (García-Fuentes \& de Torre, 2017; Kepaptsoglou et al., 2015) with the main aim to reduce air pollution related to urban mobility (Pérez et al., 2019).

There are studies using vehicle speed data for the direct estimation for the calculation of air pollutant emissions in the urban area (Zhao et al., 2017; Mitran \& Ilie, 2014; Chang \& Lin, 2018; Toșa et al., 2015, Jiang et al., 2017; Gori et al., 2014; Li et al., 2016). Many different road traffic emission models depending on speed analysis have been developed at different level of aggregation in space and time. According to Wang et al. (2018), the main classification includes a) static emission models (aggregated models, average-speed models, traffic situation models) and b) dynamic emission models (regression-based models, modal models, instantaneous models). The input data for all these is the traffic assignment model, classified according to temporal dimension: DTA, semi-dynamic traffic assignment and static traffic assignment (STA) models.

\footnotetext{
${ }^{*}$ Corresponding author. E-mail: marco.petrelli@uniroma3.it
}

\section{Copyright (C) 2020 The Author(s). Published by VGTU Press}

This is an Open Access article distributed under the terms of the Creative Commons Attribution License (http://creativecommons.org/licenses/by/4.0/), which permits unrestricted use, distribution, and reproduction in any medium, provided the original author and source are credited. 
Significant advances have been made about the accuracy of the emission models depending on the results of traffic assignment. However, these models need a large amount of data for calibration and validation and in many cases, it is very difficult to implement a satisfactory representation of the car traffic demand.

The aim of this research is to provide a simple but effective tool for the analysis of emission zones and for the evaluation of their impact in order to tackle the problem of reducing air pollutants related to road transport. The proposed methodology develops an emission indicator, a proxy measure, based on GPS instantaneous speed data. This does not represent a tool for estimating pollutant emissions, which implies the computation of emissions based on the knowledge of the level of traffic, but rather an indicator of these emissions. This indicator leads to the evaluation of the impact of different policies, as well as the adoption of control strategies in a simpler but nevertheless robust approach.

The approach is based on using data from GPS (Kong et al., 2018) for monitoring road traffic situations, in combination with the use of GIS (Liu et al., 2017). GIS tools permit the definition and representation of the spatial distribution of many variables, the pollutant emission in this case (Cai et al., 2015; Masood et al., 2017; Tenailleau et al., 2016).

This paper is a refinement of Boitor et al. (2019) innovative approach of identifying the criticalities of pollutant emissions related to road traffic. It can be considered an adequate solution especially when the development of valid DTA model is not available. It would also be useful for the evaluation of different management actions. Such an approach can be used for any specific pollutant emissions and the case study application deals with the $\mathrm{NO}_{\mathrm{x}}$ emissions .

The numerical application is applied in the case study of the city of Cluj-Napoca, Romania. The area is divided into three different speed-emission zones: Hot emission area, Medium emission area, Cold emission area. These zones were graphically represented using only the $\mathrm{NO}_{\mathrm{x}}$ indicator values.

The paper is structured as follows: Section 1 describes the methodology of the proposed tool, Section 2 presents the case study application while Section 3 shows the results of the application. Finally, conclusions are reported.

\section{Methodology}

The speed - emissions relationship is relevant for both instantaneous as well as average speed (Hu et al., 2018 ; Li et al. 2019). Instantaneous speed, along with instantaneous emissions are more accurate than average emissions (Ryu et al., 2015) for the representation of real-world situations for speeds below $20 \mathrm{~km} / \mathrm{h}$. Speed-emissions correlation is sensitive to varying real-world driving conditions in the urban context (Pathak et al., 2017), where the speed profile is a crucial parameter for fuel consumption and emission estimation, along with other factors such as time, distance, acceleration and deceleration (Zhao et al., 2016).

General process of the new tool for the evaluation of $\mathrm{NO}_{\mathrm{x}}$ emissions from road traffic is reported in Figure 1.

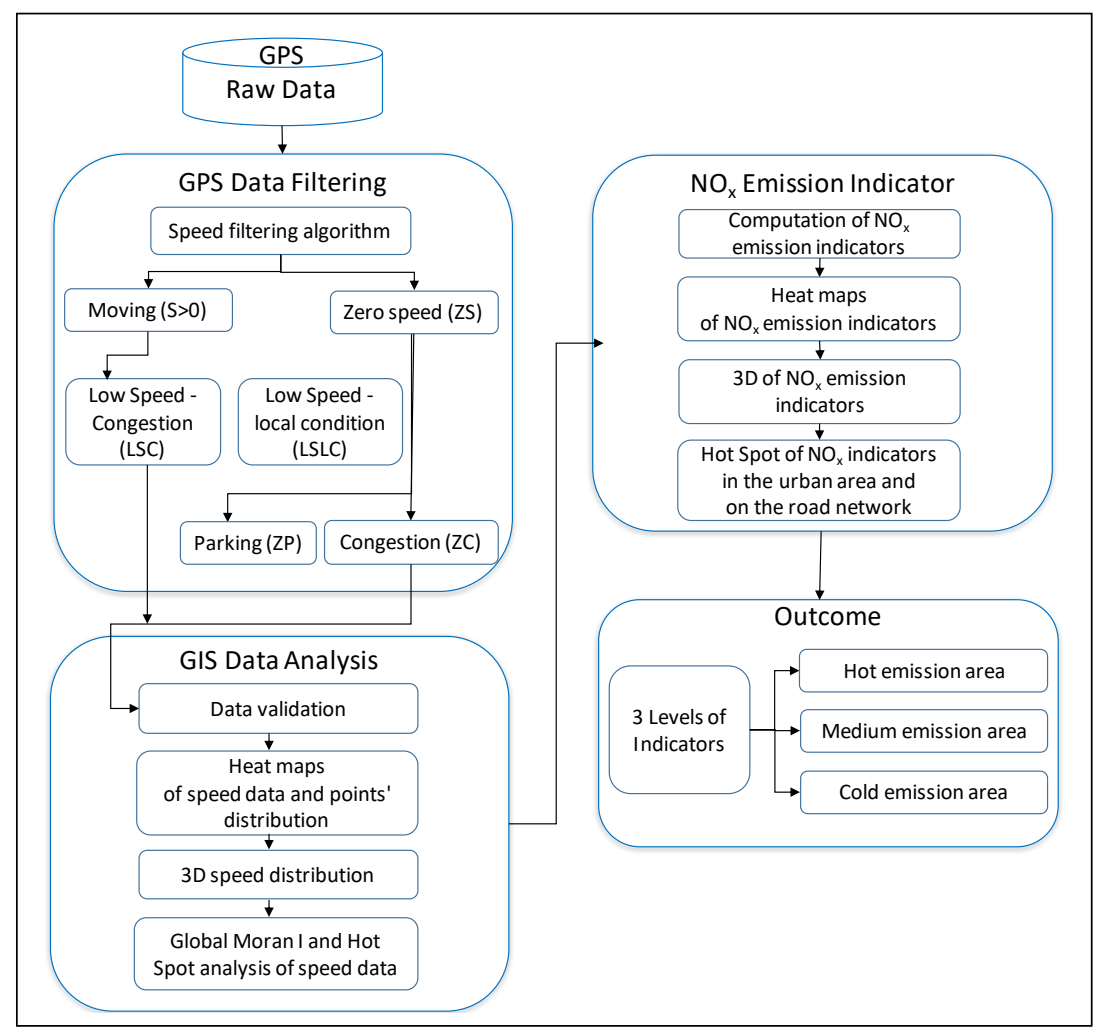

Figure 1. General process of the new tool for the evaluation of $\mathrm{NO}_{\mathrm{x}}$ emissions from road traffic 
Step 1 refers to GPS data elaboration and filtering for the numerical application after the map matching and the extraction of the GPS data for the specific area. GPS data filtering for the numerical application includes the elimination of the parking related points (ZP) which have zero speed (ZS) while maintaining the other points with zero speed, which are related to congestion (ZC). Zero speed congestion points are part of the moving process of vehicles, while parking points are excluded from the analysis. The process of filtering is also considering the moving points for ensuring that GPS instantaneous data can be considered a reliable proxy measure of the average speed of the traffic flow. For avoiding the overestimation of emission indicator, the low speed points are filtered, excluding the points representing the absence of interference with other vehicles, that generally do not produce reaction with changes in acceleration and deceleration. This is the typical condition of the local roads and they are generally considered low speed - local condition (LSLC) points. Low speed - congestion (LSC) points are part of the moving process of vehicles, while LSLC points are excluded from the analysis. This step allows the use of instantaneous speed data as satisfactory indicators of traffic density, thus considering congestion conditions.

Step 2 concerns the GIS component of the application, starting from the creation and analysis of the speed database for the citywide area. Simple visualization of the GPS points and speed weighted points in heat maps are used to check their distribution. Furthermore, the large dataset of GPS points is aggregated using a hexagonal tessellated grid (10,000 square meters hexagons). Specifically, this step involves the analysis of speed distributions and its relationships with different levels of traffic congestion. Spatial distributions are created for identifying some general patterns in the area, which can be validated with spatial statistics indicators, such as Global Moran I and Hot Spot analysis (Getis-Ord Gi*).

Step 3 deals with the calculation and visualisation of the $\mathrm{NO}_{\mathrm{x}}$ emissions indicator. The computation of the emission indicator is made using COPERT IV model (Ntziachristos et al., 2009). COPERT is considered the standard emission inventory system and it is used to estimate emissions from road transport in many countries. The hot emissions equations are considered for the calculation of the emission factor for $\mathrm{NO}_{\mathrm{x}}$ pollutant. The visualization of $\mathrm{NO}_{\mathrm{x}}$ emissions indicator is conducted using GIS tools for the emission indicator zoning process. The final output of the tool consists of a map showing the emission zones. The analysis of hot spots and cold spots is carried out using Getis-Ord $\mathrm{Gi}^{*}$ statistic, by calculating a Z-score and a p-value for each feature in the dataset. The three types of emission areas Cold, Medium, and Hot emission areas - are validated with geo-statistical analysis. For additional details about the spatial analysis and spatial statistics see Boitor et al. (2019).

\section{Case study: Cluj-Napoca, Romania}

The proposed tool is applied in the municipality of Cluj-Napoca, Romania. Cluj-Napoca is a mid-sized city with a population of more than 300,000 inhabitants and the transport system relies mostly on roads for both interurban and intra-urban mobility. In the urban road network, the speed limit is $50 \mathrm{~km} / \mathrm{h}$.

The database consists of 1,551,135 GPS points collected in the city of Cluj-Napoca, second-by-second between 09.02.2015 - 19.02.2018, using passenger car probe vehicles monitored with Track GPS application. The database contains information regarding time, latitude, longitude, speed and course for every point. 376,699 zero speed (ZS) points are divided into zero parking speeds (ZP) and zero congestion speed (ZC). The result was that $10 \%$ of the recorded points are ZP and they are excluded. A similar study (Zhao et al., 2016) presents that $87 \%$ of the recordings indicated a moving car and $13 \%$ of the recordings indicated that the car had stopped moving or the car had stopped. Furthermore, from the new dataset excluding ZP points, $20 \%$ of the points are LSLC points and they are excluded from the analysis.

The spatial distribution of the GPS points in Figure 2a shows a good coverage of the city, considering the road network, the number of observations as well as the spread locations. The speed weighted points' distribution in Figure $2 \mathrm{~b}$ shows a very good overlap with the arterial collectors and the main urban streets and it reflects traffic patterns and road traffic congestion areas. The spatial distribution of speed weighted points was further carried out to determine the spatial autocorrelation of speeds in the data set. The Global Moran analysis reported a value of 0.177713 for Global Moran's Index, a Z-score of 52.4 and a p-value of 0.00000001 . The results indicated a strong spatial autocorrelation of the speed values. This enabled the hot spot analysis (Getis-Ord Gi*) for more complex pattern analysis.

Map in Figure 2c present a more practical perspective of the speed analysis. A honeycomb network is used to aggregate the points for the analysis and some pattern determination. The honeycomb is classified using speed specific percentiles (v25, v50, v75, v85) and the posted speed (similar to v95). The speed patterns, resulting from the map can be characterized by three main aspects:

- the presence of high-speed corridors (arterial or collector street) in red, located outside the built-up area, where secondary streets give way to main traffic roads;

- the presence of high-speed clusters (red hexagons) located within the built-up area, on high-speed streets/collectors with the right of way and near signalized intersection;

- the presence of low-speed hexagons on the main road corridors close to signalized intersections or roundabouts. 

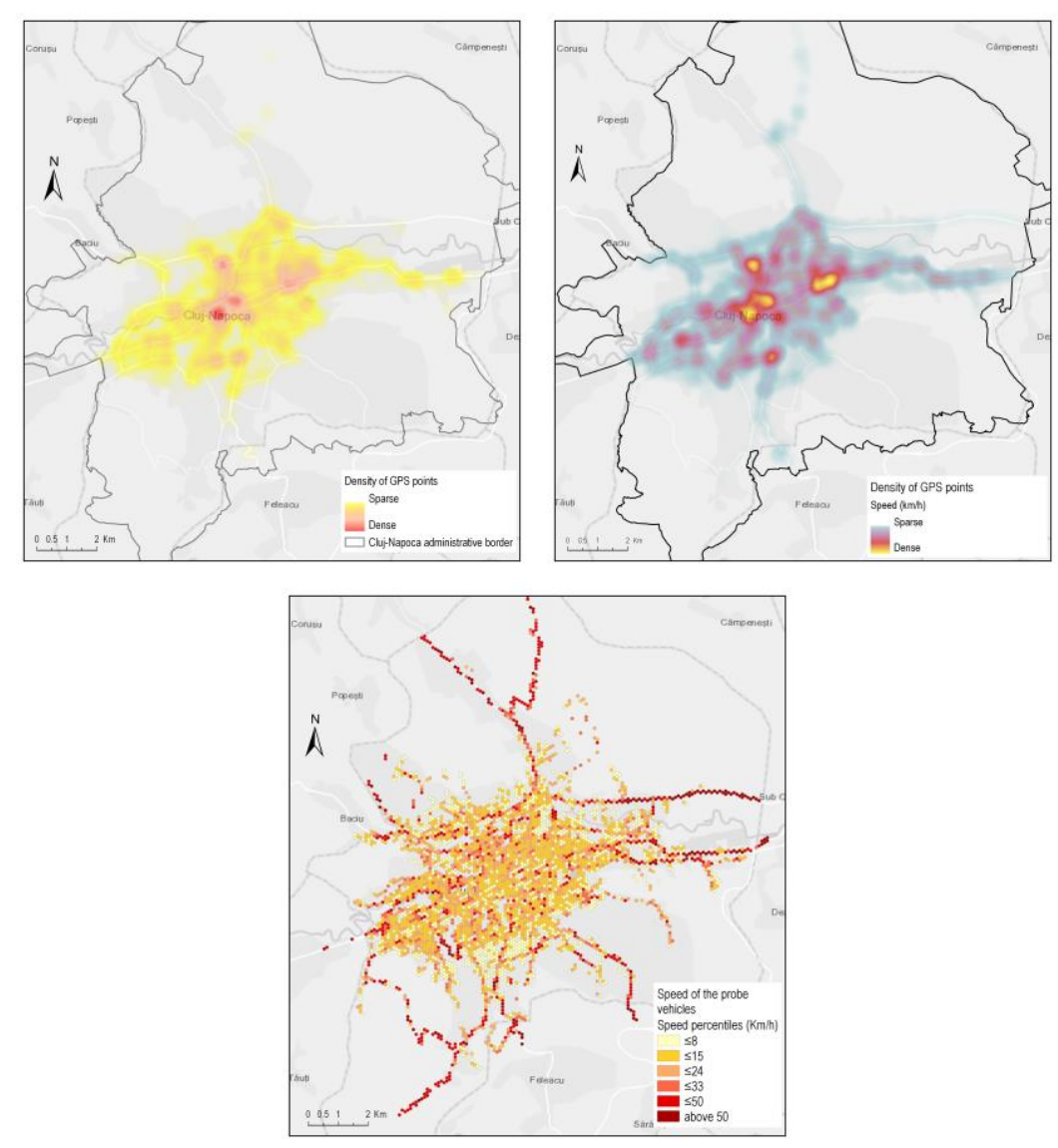

Figure 2. Spatial distribution of the GPS points in the dataset: a) density of points;

b) density of speed weighted points; c) honeycomb speed distribution

The numerical application is carried out by using only passenger cars since the percentage of heavy traffic vehicles in the general flow in Cluj-Napoca is very low, largely under $10 \%$ based on numerous traffic censuses in different points in the city. Therefore, the study includes only the speed data of the passenger cars. The NOx evaluation in COPERT model is made for the passenger cars disaggregated by type of vehicle and legislation standard. Considering the data from the National Institute for Statistics (2018), at the national level there are 55\% of gasoline passenger cars and $45 \%$ diesel passenger cars. The average age of the passenger car fleet in the city is related to the emission standard Euro 4.

\section{Results of the application/spatial analysis of data}

The results of the application of the tool in Cluj-Napoca presented in this section are focused on the analysis of the results about the emissions indicator. According to the methodology, GIS-based methods are used, such as heat maps, spatial distributions, and hotspots. GIS representation for emission indicator visualization is conducted using the honeycomb network and different ranges for the classification of the cells.

Figure 3 a presents the distribution of emissions indicator weighted points. It shows that the high concentration of emissions is found in the central area of the city, while the sparse density covering the urban areas suggest that the points are spread all over the urban built area. High concentration of NOx indicator values is also found in congested intersections and on the road that are not modernized. Therefore, the details about the state of the pavement should be considered for further and more detailed analysis.

The Global Moran analysis of the NOx emission factor reports a value of 0.091235 for Global Moran's Index, a Z-score of 26.9 and a p-value of 0.00000001 . The results indicate a strong spatial autocorrelation of the NOx emission indicator values.

Figure $3 \mathrm{~b}$ shows the results of the hot-spot analysis. First, it underlines that, unlike the spatial distribution of speed data, the NOx emission indicator presents high values, correlated to the high NOx emission case, in many places throughout the city, not only limited to the central part of the city, where spread data show the existence of the traffic congestion case. The high emission area distribution is due to the presence of the two worst cases: slow speed for congested traffic and high-speed vehicles with increasing fuel consumption. The classification of the road transport 
system including all its components for the evaluation of the ecological status of these areas was also proposed by Andrei and Condurat (2018). Taking into account this approach, the emission zones in terms of NOx pollutant are a good indicator for identifying the need of intervention. Specifically, the use of Getis- Ord Gi* statistic underlines the presence of three different areas according to the point of view of pollutant emissions. This adjustment of the results, by filtering and clustering the points, enables a more homogeneous and clear distribution of the emission areas in the urban area model, which is more consistent with real traffic conditions (Figure 4b). Therefore, mapping the areas based on the values of the NOx emission indicator (Figure 4a), it is possible to observe that the proxy indicator allows to obtain results similar to the ones derived from the classic emission models.

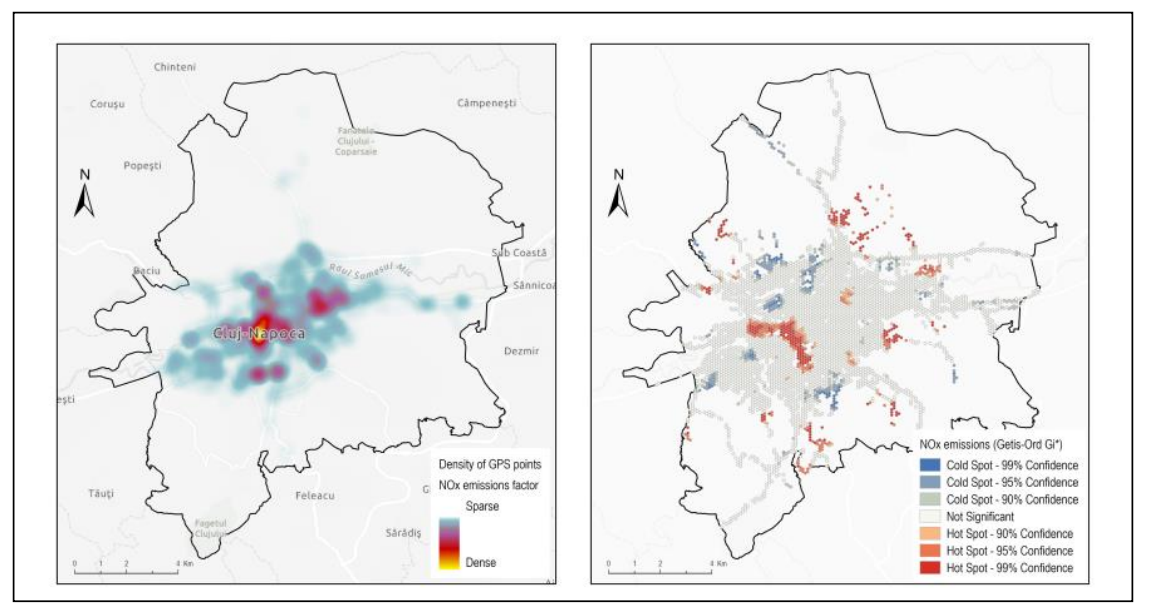

Figure 3. Computation of NOx emission zones: a) density of NOx emission indicator/heat map; b) hot-spot results of emission indicator

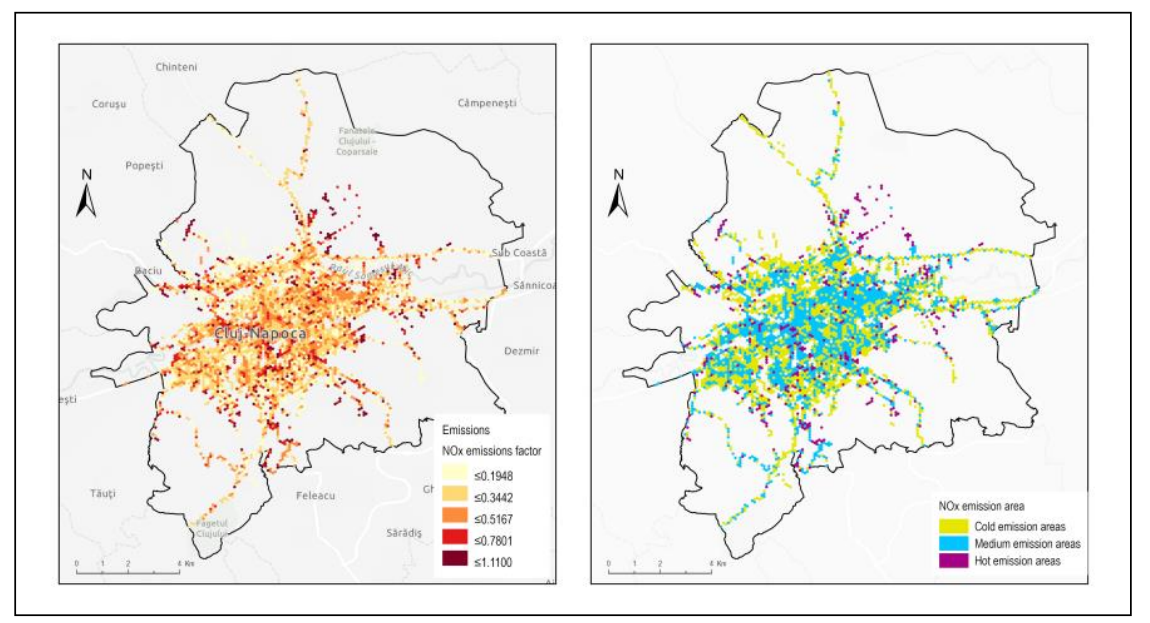

Figure 4. Computation of NOx emission zones: a) NOx emission indicator classification in honeycomb network;

b) NOx emission areas classification

\section{Conclusions}

This section reports the description of the methodology proposed and the results of the numerical application of this to the real case study of the city of Cluj-Napoca. The basis of the method is related to the use of new technologies that allow the collection of an extensive amount of data referring to real vehicle travel history. These data, as also described in the literature, are used for developing tools involving the evaluation of the impact of various policies for decreasing pollutants emissions, especially in urban areas.

Therefore, the aim of this study is to propose a simple, but effective tool for the analysis of emission zones and for the evaluation of the impact of management policies. The proposed methodology develops an emission indicator, a proxy measure, based on GPS instantaneous speed data. This does not represent a tool for estimating pollutant emissions, which implies the computation of emissions based on the knowledge of the level of traffic, but rather an indicator of these emissions.

For this purpose, the evaluation and visualization of NOx emissions indicator based on GPS speed data from several probe vehicles is conducted in four steps. The first step of the tool refers to raw data processing, namely map 
matching and extraction of specific area. Secondly, GPS data filtering is conducted in order to identify ZP points associated with parking and LSLC points, which are excluded from the emission indicator analysis. Then, the validation is carried out by means of GIS tools. At last, the emission indicator is obtained and validated. About the application carried out in Cluj-Napoca, it is possible to observe that the emission zones were classified based on the values of the NOx emission indicator. A share of $11 \%$ Hot emission areas, $44 \%$ Medium emission areas and $45 \%$ Cold emission areas resulted. Moreover, Hot emission areas are easy to spot and further analyse. $\mathrm{NO}_{\mathrm{x}}$ instantaneous emissions have been found to be more reliable for capturing congestion impact.

The integration of emission data with GIS is an effective method to perform complex environmental analysis by means of pollutant spatial distribution. The results show the utility of the tool for policy and planning process of road traffic management, due to its ease of application and consistency especially for the definition of critical areas and prioritising of the improvements with mobility projects. The input data can be dynamically updated, which implies the repetition of the numerical application.

Further efforts have to be done to better refine the method. The efforts should include the following aspects: (1) the study is focused on a small fleet of probe vehicles. More complete analyses, on a wider and more robust sample of probe vehicles need to be conducted; (2) the study provides a methodology that the use of the speed data related to single vehicles. The activities carried out are mainly focused on the spatial analysis of the data from GPS points but there is the need of additional refinements in order to study the temporal changes of speed vehicles as well, for defining congested and free-flow conditions in a more robust way; (3) further development will deal with the validation of the model using two possible sets of data for comparison: the real-world data concerning pollutants emission and concentration from sensors and the emissions estimated using a detailed traffic model based on DTA. Another important step for the overall validation of the tool will test the capacity to evaluate various strategies to reduce of emissions such as the congestion mitigation actions or speed management techniques.

\section{References}

Afotey, B. N., Sattler, M. L., Mattingly, S. P., \& Chen, V. C. (2013). Statistical model for estimating carbon dioxide emissions from a light-duty gasoline vehicle. Journal of Environmental Protection, 4, 8-15. https://doi.org/10.4236/jep.2013.48A1002

Alam, M. S., Duffy, P., Hyde, B., \& McNabola, A. (2017). Improvement in the estimation and back-extrapolation of CO 2 emissions from the Irish road transport sector using a bottom-up data modelling approach. Transportation Research Part D: Transport and Environment, 56, 18-32. https://doi.org/10.1016/j.trd.2017.07.011

Andrei, R., \& Condurat, M. (2018). Evaluation of ecological impact of roads function of their technical condition and the intensity of traffic flow (II) Practical approach. Case studies and technical recommendations. Buletinul Institutului Politehnic din lasi. Sectia Constructii, Arhitectura, 64, 109-123. http://www.bipcons.ce.tuiasi.ro/Archive/652.pdf

Banica, A., Bobric, E. D., Cazacu, M. M., Timofte, A., Gurlui, S., \& Breaban, I. G. (2017). Integrated assessment of exposure to traffic-related air pollution in Iasi City, Romania. Environmental Engineering and Management Journal, 16, $2147-2163$. https://doi.org/10.30638/eemj.2017.222

Barth, M., \& Boriboonsomsin, K. (2008). Real-world carbon dioxide impacts of traffic congestion. Transportation Research Record: Journal of the Transportation Research Board, 2058, 163-171. https://doi.org/10.3141/2058-20

Boitor, R. M., Cadar, R. D., Măran, P. D., Mannini, L., \& Petrelli, M. (2019). A new tool for the evaluation of CO 2 emissions from road traffic: a case study in Cluj-Napoca, Romania. Environmental Engineering \& Management Journal, 18, $2083-2093$. https://doi.org/10.30638/eemj.2019.198

Cai, M., Zou, J., Xie, J., \& Ma, X. (2015). Road traffic noise mapping in Guangzhou using GIS and GPS. Applied Acoustics, 87, 94-102. https://doi.org/10.1016/j.apacoust.2014.06.005

Chang, C. T., \& Lin, T. P. (2018). Estimation of carbon dioxide emissions generated by building and traffic in Taichung city. Sustainability, 10, 112-130. https://doi.org/10.3390/su10010112

Condurat, M. (2016). Chains of causality associated with the environmental impact of road transport system. Journal of Sustainable Architecture and Civil Engineering, 14, 20-30. https://doi.org/10.5755/j01.sace.14.1.14658

Covrig, I., Oroian, I., Odagiu, A., Holonec, L., \& Oroian, E. (2016). A. hippocastanum L. and T. cordata mill. as biomonitoring plants for air pollution in urban areas. A case study: City of Cluj-Napoca. Environmental Engineering \& Management Journal (EEMJ), 15(5), 995-1002. http://eemj.eu/index.php/EEMJ/article/view/2919

EC. (2013). COM (2013) 913 final. Together towards competitive and resource efficient urban mobility, A concept for sustainable urban mobility plans, Annex 1. https://ec.europa.eu/transport/sites/transport/files/themes/urban/doc/ump/com\%282013\%29913-annex_en.pdf

ELTIS. (2014). Guidelines. Developing and implementing a sustainable urban mobility plan. http://www.eltis.org/sites/default/files/sump_guidelines_en.pdf

García-Fuentes M., \& de Torre C. (2017). Towards smarter and more sustainable regenerative cities: the REMOURBAN model. Entrepreneurship and Sustainability Issues, 4, 328-338. https://doi.org/10.9770/jesi.2017.4.3S(8)

Gori, S., La Spada, S., Mannini, L., \& Nigro, M. (2014). Emission dynamic meso-simulation model to evaluate traffic strategies in congested urban networks. IET Intelligent Transport Systems, 9, 333-342. https://doi.org/10.1049/iet-its.2013.0026

Grote, M., Williams, I., Preston, J., \& Kemp, S. (2018). A practical model for predicting road traffic carbon dioxide emissions using Inductive Loop Detector data. Transportation Research Part D: Transport and Environment, 63, 809-825.

https://doi.org/10.1016/j.trd.2018.06.026 
Hu, X., Xu, D., \& Wan, Q. (2018). Short-term trend forecast of different traffic pollutants in Minnesota based on spot velocity conversion. International Journal of Environmental Research and Public Health, 15(9), 1925.

Jiang, Z., Chen, X. M., \& Ouyang, Y. (2017). Traffic state and emission estimation for urban expressways based on heterogeneous data. Transportation Research Part D: Transport and Environment, 53, 440-453. https://doi.org/10.1016/j.trd.2017.04.042

Kepaptsoglou, K., Karlaftis, M. G., Gkotsis, I., Vlahogianni, E., \& Stathopoulos A. (2015). Urban regeneration in historic downtown areas: an ex-ante evaluation of traffic impacts in Athens, Greece. International Journal of Sustainable Transportation, 9, 478489. https://doi.org/10.1080/15568318.2013.811331

Kong, X., Li, M., Ma, K., Tian, K., Wang, M., Ning, Z., Xia, F. (2018). Big trajectory data: A survey of applications and services. IEEE Access, 6, 58295-58306. https://doi.org/10.1109/ACCESS.2018.2873779

Laña, I., Del Ser, J., Padró, A., Vélez, M., \& Casanova-Mateo, C. (2016). The role of local urban traffic and meteorological conditions in air pollution: A data-based case study in Madrid, Spain. Atmospheric Environment, 145, 424-438. https://doi.org/10.1016/j.atmosenv.2016.09.052

Li, M., Yu, L., Zhai, Z., He, W., \& Song, G. (2016). Development of emission factors for an urban road network based on speed distributions. Journal of Transportation Engineering, 142, 1-9. https://doi.org/10.1061/(ASCE)TE.1943-5436.0000858

Liu, Y., Yan, X., Wang, Y., Yang, Z., \& Wu, J. (2017). Grid mapping for spatial pattern analyses of recurrent urban traffic congestion based on taxi GPS sensing data. Sustainability, 9, 533-548. https://doi.org/10.3390/su9040533

Masood, A., Kafeel, A., \& Shamshad, A. (2017). Urban roadside monitoring, modeling and mapping of air pollution. Applied Journal of Environmental Engineering Science, 3, 179-194.

Matz, C. J., Stieb, D. M., Egyed, M., Brion, O., \& Johnson, M. (2018). Evaluation of daily time spent in transportation and trafficinfluenced microenvironments by urban Canadians. Air Quality, Atmosphere \& Health, 11, 209-220. https://doi.org/10.1007/s11869-017-0532-6

Mitran, G., \& Ilie, S. (2014). Method for inventorying CO emissions from road traffic in urban areas through transport modeling. Environmental Engineering and Management Journal, 13(8), 1945-1956.

National Institute for Statistics - ROMANIA. (2018). Transport equipment, vehicles registered and road traffic accidents. http://www.insse.ro/cms/ro/content/mijloace-de-transport-vehicule-înmatriculate-şi-accidente-de-circulație-rutieră

Ntziachristos, L., Gkatzoflias, D., Kouridis, C., \& Samaras Z. (2009). COPERT: A European road transport emission inventory model (pp. 491-504). Springer. https://doi.org/10.1007/978-3-540-88351-7_37

Pathak, S. K., Singh, Y., Sood, V., \& Channiwala, S. A. (2017). On-road vehicle driving and energy requirements and impact on unregulated exhaust emissions under urban driving conditions. SAE International Journal of Engines, 10, $1866-1879$. https://doi.org/10.4271/2017-01-1013

Pérez, J., de Andrés, J. M., Borge, R., de la Paz, D., Lumbreras, J., \& Rodríguez, E. (2019). Vehicle fleet characterization study in the city of Madrid and its application as a support tool in urban transport and air quality policy development. Transport Policy, 74, 114-126.

Ryu, B. Y., Jung, H. J., \& Bae, S. H. (2015). Development of a corrected average speed model for calculating carbon dioxide emissions per link unit on urban roads. Transportation Research Part D: Transport and Environment, 34, $245-254$. https://doi.org/10.1016/j.trd.2014.10.012

Roșu, L., Istrate, M., \& Bănică, A. (2018). Passenger car dependency and consequent air pollutants emissions in Iasi metropolitan area (romania). Environmental Engineering and Management Journal, 17(4), 865-875. http://eemj.eu/index.php/EEMJ/article/view/3551

Tenailleau, Q. M., Bernard, N., Pujol, S., Parmentier, A. L., Boilleaut, M., Houot, H., \& Mauny, F. (2016). Do outdoor environmental noise and atmospheric $\mathrm{NO}_{2}$ levels spatially overlap in urban areas. Environmental Pollution, 214, 767-775. https://doi.org/10.1016/j.envpol.2016.04.082

Tongwane, M., Piketh, S., Stevens, L., \& Ramotubei T. (2015). Greenhouse gas emissions from road transport in South Africa and Lesotho between 2000 and 2009. Transportation Research Part D: Transport and Environment, 37, 1-13. https://doi.org/10.1016/j.trd.2015.02.017

Toşa, C., Antov, D., Köllő, G., Rõuk, H., \& Rannala M. (2015). A methodology for modelling traffic related emissions in suburban areas. Transport, 30, 80-87. https://doi.org/10.3846/16484142.2013.819034

Wang, Y., Szeto, W. Y., Han, K., \& Friesz, T. L. (2018). Dynamic traffic assignment: A review of the methodological advances for environmentally sustainable road transportation applications. Transportation Research Part B: Methodological, 111, 370394.

Zhang, L., Long, R., Chen, H., \& Geng, J. (2018). A review of China's road traffic carbon emissions. Journal of Cleaner Production, 207, 569-581. https://doi.org/10.1016/j.jclepro.2018.10.003

Zhao, X., Carling, K., \& Håkansson, J. (2016). Residential planning, driver mobility and $\mathrm{CO}_{2}$ emission. Working papers in transport, tourism, information technology and microdata analysis, 5. Dalarna University. https://www.diva-portal.org/smash/get/diva2:1067701/FULLTEXT01.pdf

Zhao, X., Carling, K., \& Håkansson, J. (2017). Residential planning, driver mobility and $\mathrm{CO}_{2}$ emission: a microscopic look at Borlänge in Sweden. European Planning Studies, 25(9), 1597-1614. 